\title{
Redução de fósforo em dietas para frangos com base em valores de equivalência da fitase
}

\author{
Luciana de Paula Naves ${ }^{(1)}$, Paulo Borges Rodrigues(1), Antônio Gilberto Bertechini(1), \\ Eduardo Machado Costa Lima ${ }^{(1)}$, Levy do Vale Teixeira ${ }^{(1)}$, Renata Ribeiro Alvarenga ${ }^{(1)}$, \\ Nicole Batelli de Souza Nardelli(1), David Henrique de Oliveira(1) e Marcelo Henrique de Oliveira(1)
}

\begin{abstract}
(1)Universidade Federal de Lavras, Departamento de Zootecnia, Campus Universitário, s/no, Caixa Postal 3037, CEP 37200000 Lavras, MG, Brasil. Email: luciana.naves@hotmail.com, pborges@dzo.ufla.br, bertechini@dzo.ufla.br, lima_emc@yahoo.com.br, levydvt@gmail.com, renatazootec@yahoo.com.br, nicole-nardelli@hotmail.com, davidhenriqueoliveira@hotmail.com, marchen02@hotmail.com
\end{abstract}

\begin{abstract}
Resumo - O objetivo deste trabalho foi avaliar o uso de valores de equivalência da fitase como base para redução de fósforo disponível (P-disp) em dietas para frangos. Foram avaliados dez planos nutricionais com seis repetições de 15 aves cada uma. Avaliaram-se: desempenho, teor de cinzas na tíbia e custo da ração. De 1 a 7 e de 36 a 42 dias de idade, as aves receberam dieta basal; de 8 a 21 dias, dieta sem fitase contendo $3,9 \mathrm{~g} \mathrm{~kg}^{-1}$ de P-disp e quatro dietas com fitase contendo de 1,1 a $2,5 \mathrm{~g} \mathrm{~kg}^{-1}$ de P-disp; e de 22 a 35 dias, dieta sem fitase contendo 3,4 $\mathrm{g} \mathrm{kg}^{-1}$ de P-disp mais dieta com fitase contendo 1,6 $\mathrm{g} \mathrm{kg}^{-1}$ de P-disp. O melhor plano nutricional foi composto pelas dietas: 4,7 $\mathrm{g} \mathrm{kg}^{-1}$ de P-disp sem fitase (1 a 7 dias); $2,0 \mathrm{~g} \mathrm{~kg}^{-1}$ de P-disp suplementada com fitase ( 8 a 21 dias); 3, $4 \mathrm{~g} \mathrm{~kg}^{-1}$ de P-disp em ração sem fitase (22 a 35 dias); e 3,0 $\mathrm{g} \mathrm{kg}^{-1}$ de P-disp em ração sem fitase (36 a 42 dias). A redução do P-disp ocorre no período de 8 a 21 dias de idade e corresponde a 2,0 $\mathrm{g} \mathrm{kg}^{-1}$ de ração suplementada com fitase.
\end{abstract}

Termos para indexação: avicultura, cinza óssea, desempenho, enzima, fitato, nutrição.

\section{Reduction of phosphorus in broiler diets based on equivalency values of phytase}

\begin{abstract}
The objective of this work was to evaluate the use of equivalency values of phytase as a basis for reduction of available phosphorus (aP) in broiler diets. Ten nutritional programs were evaluated with six replicates of 15 birds each. The following were evaluated: performance, tibia ash content, and feed costs. From 1 to 7 and 36 to 42 days of age, the birds received basal diet; from 8 to 21 days, diet without phytase containing $3.9 \mathrm{~g} \mathrm{~kg}^{-1} \mathrm{aP}$ and four diets with phytase containing from 1.1 to $2.5 \mathrm{~g} \mathrm{~kg}^{-1} \mathrm{aP}$; and from 22 to 35 days, diet without phytase containing $3.4 \mathrm{~g} \mathrm{~kg}^{-1}$ aP plus diet with phytase containing $1.6 \mathrm{~g} \mathrm{~kg}^{-1}$ aP. The best nutritional plan was formed by the diets: $4.7 \mathrm{~g} \mathrm{~kg}^{-1}$ aP without phytase (1 to 7 days); $2.0 \mathrm{~g} \mathrm{~kg}^{-1}$ aP supplemented with phytase (8 to 21 days); $3.4 \mathrm{~g} \mathrm{~kg}^{-1} \mathrm{aP}$ in feed without phytase (22 to 35 days); and $3.0 \mathrm{~g} \mathrm{~kg}^{-1} \mathrm{aP}$ in feed without phytase ( 36 to 42 days). The reduction of aP occurs in the period from 8 to 21 days of age and corresponds to $2.0 \mathrm{~g} \mathrm{~kg}^{-1}$ of feed supplemented with phytase.
\end{abstract}

Index terms: aviculture, bone ash, performance, enzyme, phytate, nutrition.

\section{Introdução}

Os monogástricos apresentam baixa atividade de fitase endógena, logo, fitases microbianas têm sido adicionadas à dieta de frangos de corte para aumentar o aproveitamento do fósforo $(\mathrm{P})$ fítico presente nos ingredientes de origem vegetal da ração (Karimi et al., 2011). Como benefícios secundários, mas não menos importantes, o uso da fitase na nutrição avícola reduz o custo da ração pela menor inclusão de fonte de $\mathrm{P}$ inorgânico, melhora o aproveitamento de outros nutrientes da dieta pela redução da capacidade complexante do fitato e diminui o impacto ambiental pela menor excreção de $\mathrm{P}$ (Bedford \& Partridge, 2010). Recentemente, foi lançada no mercado uma 6-fitase comercial produzida a partir de genes sintéticos (com sequência de nucleotídeos semelhante ao do gene que codifica a fitase de Citrobacter braakii) introduzidos em Aspergillus oryzae. A partir daí, alguns trabalhos científicos têm sido realizados com essa enzima (Lichtenberg et al., 2011; Shaw et al., 2011).

No entanto, determinar a formulação ideal da dieta, para permitir máxima eficiência da fitase exógena e menor excreção de $\mathrm{P}$, associados à manutenção 
do desempenho e da adequada mineralização óssea dos frangos de corte, não é tarefa simples, em razão da quantidade de fatores envolvidos. Entre estes fatores, destacam-se a linhagem, o sexo e a idade das aves, o tipo de fitase utilizada, bem como o seu nível de suplementação na dieta e a própria composição percentual de P na ração (Bedford \& Partridge, 2010).

Em experimento de metabolismo, Naves (2012) avaliou o efeito do nível de inclusão de 6 -fitase $(0$, $750,1.500$ e 2.250 unidades de atividade da fitase, FTU, por $\mathrm{kg}$ de dieta), em dieta deficiente em $\mathrm{P}$ disponível (P-disp), sobre o coeficiente de hidrólise do $\mathrm{P}$ fítico, cujos valores foram determinados nas dietas e nas excretas, e concluiu que $1.500 \mathrm{FTU} \mathrm{kg}^{-1}$ proporcionaram o maior aproveitamento do $\mathrm{P}$ fítico $(88,45 \%)$. Experimentos posteriores mostraram que o uso de 1.500 FTU da 6-fitase de C. braakii por kg de ração equivalem a 1,4 e $1,8 \mathrm{~g} \mathrm{~kg}^{-1}$ de $\mathrm{P}$ nos períodos de criação específicos de 8 a 21 e de 22 a 35 dias de idade, respectivamente. Entretanto, os dois valores de equivalência de $\mathrm{P}$ anteriormente citados foram determinados em dois experimentos independentes um do outro. Assim, para a seleção de um plano nutricional com redução de P-disp em dietas de frangos de corte, faz-se necessário avaliar se é viável ou não o uso contínuo da 6-fitase de $C$. braakii na ração durante o período de criação de 8 a 35 dias de idade, em um único lote de frangos.

$\mathrm{O}$ uso de fitase exógena na dieta baseia-se na redução do teor de P-disp na ração (na forma de $\mathrm{P}$ inorgânico) acompanhada da correspondente inclusão da enzima, segundo o valor de equivalência de $\mathrm{P}$ previamente estabelecido. Dessa forma, espera-se que o teor de P-disp presente na ração somado ao teor de $\mathrm{P}$ disponibilizado pela fitase seja igual à exigência de P do frango de corte (Jendza et al., 2006). Contudo, a exigência de $\mathrm{P}$ para frangos de corte recomendada pode estar superestimada, e, se este for o caso, a atual redução do teor de P-disp proposta para dietas suplementadas com fitase pode estar subestimada (Slominski, 2011). Nesse sentido, é possível reduzir ainda mais o nível de P-disp na dieta e o teor de P que será excretado pelo animal. Porém, é necessário acompanhar a resposta de desempenho e mineralização óssea das aves para assegurar que não haja prejuízos para a cadeia produtiva.
O objetivo deste trabalho foi avaliar o uso de valores de equivalência da fitase como base para redução de P-disp em dietas para frangos.

\section{Material e Métodos}

O experimento foi realizado em Junho e Julho de 2013, no Setor de Avicultura do Departamento de Zootecnia, da Universidade Federal de Lavras, MG. Foram adquiridos 900 frangos de corte machos da linhagem Cobb-500 (pintainhos de um dia de idade) criados até os sete dias em galpão de alvenaria com piso coberto com maravalha. Durante esse período, os frangos foram alimentados com dieta basal formulada para atender suas exigências nutricionais, de acordo com Rostagno et al. (2011) (Tabela 1).

No oitavo dia de idade, as aves foram: pesadas individualmente em balança digital, modelo Prix 3 (Toledo, São Bernardo do Campo, SP), com capacidade máxima de $2 \mathrm{~kg}$ e precisão de $2 \mathrm{~g}$; separadas por faixas de peso; e distribuídas conforme os dez planos nutricionais (PN). Para a descrição das dietas constituintes dos $\mathrm{PN}$, adotou-se o sinal $(+)$ para indicar que a ração foi suplementada com $1.500 \mathrm{FTU} \mathrm{kg}^{-1}$ da fitase de C. braakii e, em contrapartida, o sinal (-) para indicar que a ração não foi suplementada com fitase. As composições das rações de cada PN, em $\mathrm{g} \mathrm{kg}^{-1}$ de P-disp, com adição (+) ou não (-) de fitase, conforme o período de criação dos frangos de corte, estão apresentadas na Tabela 2.

Os PN foram avaliados em seis repetições de 15 aves cada uma. As 900 aves foram distribuídas em 60 unidades experimentais (boxes de dimensões $1,5 \times 2,0 \mathrm{~m}$ cada um), sendo 30 unidades com aves leves (peso médio de $2,617 \pm 0,020 \mathrm{~kg}$ ) e $30 \mathrm{com}$ aves pesadas (peso médio de 2,880 $\pm 0,018 \mathrm{~kg}$ ). Utilizou-se o delineamento de blocos ao acaso, com três repetições por bloco. O piso do box foi coberto com maravalha e provido de comedouro e bebedouro pendulares, além de lâmpada incandescente de 100 watts utilizada como fonte de iluminação e aquecimento, conforme necessário.

Nos diferentes PN, o teor de P-disp foi ajustado tendo-se alterado a inclusão do fosfato bicálcico com as respectivas substituições por caulim (inerte) (Tabela 1). Para o período de criação de 8 a 21 dias de idade, foi considerada a exigência atual de $3,9 \mathrm{~g} \mathrm{~kg}^{-1}$ de P-disp recomendada por Rostagno et al. (2011) e 
que a fitase disponibiliza parte do $\mathrm{P}$ fítico presente na dieta em valor equivalente a $1,4 \mathrm{~g} \mathrm{~kg}^{-1}$ de P-disp. Este valor foi estabelecido em experimento preliminar pelo grupo de pesquisa do presente trabalho, com base na técnica da curva-padrão (na forma de $\mathrm{P}$ originado de fosfato bicálcico) e nos parâmetros ganho de peso e teor de cinzas na tíbia. Para o período de criação de 22 a 35 dias de idade, considerou-se a exigência de $3,4 \mathrm{~g} \mathrm{~kg}^{-1}$ de P-disp (Rostagno et al., 2011) e o valor de equivalência da fitase de $1,8 \mathrm{~g} \mathrm{~kg}^{-1}$ de P-disp, segundo o estabelecido por Naves (2012), pela técnica da curvapadrão.

As dietas foram fareladas, à base de milho e farelo de soja, e, assim como a água, foram fornecidas à vontade para os frangos. As rações e as sobras, bem como os frangos de cada unidade experimental, foram pesadas e registradas no oitavo, no trigésimo quinto e no quadragésimo segundo dia de idade em balanças digitais, modelo Prix 3 (Toledo, São Bernardo do Campo, SP), com capacidade máxima de 2, 6 ou

Tabela 1. Composição e valor nutricional das dietas experimentais com diferentes concentrações de P-disp $(4,7,3,9,2,5$, 2,0,1,5, 1,1,3,4, 1,6, 3,0 $\mathrm{g} \mathrm{kg}^{-1}$ de ração) avaliadas nas diferentes fases de criação dos frangos de corte machos da linhagem Cobb-500.

\begin{tabular}{|c|c|c|c|c|c|c|c|c|c|}
\hline \multirow{2}{*}{$\begin{array}{l}\text { Ingrediente } \\
\left(\mathrm{g} \mathrm{kg}^{-1} \text { de matéria natural) }\right.\end{array}$} & \multirow{2}{*}{$\frac{1 \text { a } 7 \text { dias }}{4,7^{(1)}}$} & \multicolumn{5}{|c|}{8 a 21 dias } & \multicolumn{2}{|c|}{22 a 35 dias } & \multirow{2}{*}{$\frac{36 \text { a } 42 \text { dias }}{3,0^{(1)}}$} \\
\hline & & $3,9^{(1)}$ & 2,5 & 2,0 & 1,5 & 1,1 & $3,4^{(1)}$ & 1,6 & \\
\hline Milho & 556,3 & 595,3 & 595,3 & 595,3 & 595,3 & 595,3 & 621,6 & 621,6 & 671,6 \\
\hline Farelo de soja & 382,1 & 347,4 & 347,4 & 347,4 & 347,4 & 347,4 & 315,2 & 315,2 & 272,6 \\
\hline Óleo de soja & 20,1 & 20,5 & 20,5 & 20,5 & 20,5 & 20,5 & 30,4 & 30,4 & 27,6 \\
\hline Fosfato bicálcico & 17,9 & 14,2 & 7,0 & 4,6 & 2,0 & 0,0 & 12,0 & 2,5 & 10,1 \\
\hline Calcário & 8,8 & 8,9 & 13,7 & 15,3 & 17,0 & 18,4 & 8,3 & 14,6 & 7,4 \\
\hline Sal comum & 5,1 & 4,8 & 4,8 & 4,8 & 4,8 & 4,8 & 4,6 & 4,6 & 4,4 \\
\hline DL-metionina & 3,6 & 2,9 & 2,9 & 2,9 & 2,9 & 2,9 & 2,6 & 2,6 & 2,4 \\
\hline L-lisina $\mathrm{HCl}$ & 2,9 & 2,2 & 2,2 & 2,2 & 2,2 & 2,2 & 1,9 & 1,9 & 2,4 \\
\hline L-treonina & 1,0 & 0,6 & 0,6 & 0,6 & 0,6 & 0,6 & 0,4 & 0,4 & 0,5 \\
\hline Suplemento mineral ${ }^{(2)}$ & 0,5 & 0,5 & 0,5 & 0,5 & 0,5 & 0,5 & 0,5 & 0,5 & 0,5 \\
\hline Suplemento vitamínico ${ }^{(3)}$ & 0,5 & 0,5 & 0,5 & 0,5 & 0,5 & 0,5 & 0,4 & 0,4 & 0,3 \\
\hline Cloreto de colina & 0,5 & 0,5 & 0,5 & 0,5 & 0,5 & 0,5 & 0,4 & 0,4 & 0,2 \\
\hline Bacitracina de zinco & 0,2 & 0,2 & 0,2 & 0,2 & 0,2 & 0,2 & 0,2 & 0,2 & 0,0 \\
\hline Salinomicina $12 \%$ & 0,5 & 0,5 & 0,5 & 0,5 & 0,5 & 0,5 & 0,5 & 0,5 & 0,0 \\
\hline Inerte (caulim) & 0,0 & 1,0 & 3,3 & 4,1 & 5,0 & 5,6 & 1,0 & 4,0 & 0,0 \\
\hline Fitase $^{(4)}$ & 0,0 & 0,0 & 0,156 & 0,156 & 0,156 & 0,156 & 0,0 & 0,156 & 0,0 \\
\hline Total & 1.000 & 1.000 & 1.000 & 1.000 & 1.000 & 1.000 & 1.000 & 1.000 & 1.000 \\
\hline Custo da ração $\left(\mathrm{R} \$ \mathrm{~kg}^{-1}\right)$ & 0,868 & 0,828 & 0,824 & 0,821 & 0,818 & 0,815 & 0,820 & 0,814 & 0,779 \\
\hline \multicolumn{10}{|l|}{ Composição nutricional calculada ${ }^{(5)}$} \\
\hline Energia metabolizável $\left(\mathrm{kcal} \mathrm{kg}^{-1}\right)$ & 2.950 & 3.000 & 3.000 & 3.000 & 3.000 & 3.000 & 3.100 & 3.100 & 3.150 \\
\hline Proteína bruta $\left(\mathrm{g} \mathrm{kg}^{-1}\right)$ & 222,0 & 208,0 & 208,0 & 208,0 & 208,0 & 208,0 & 195,0 & 195,0 & 180,0 \\
\hline Cálcio $\left(\mathrm{g} \mathrm{kg}^{-1}\right)$ & 9,2 & 8,2 & 8,2 & 8,2 & 8,2 & 8,2 & 7,3 & 7,3 & 6,4 \\
\hline Fósforo disponível $\left(\mathrm{g} \mathrm{kg}^{-1}\right)$ & 4,7 & 3,9 & 2,5 & 2,0 & 1,5 & 1,1 & 3,4 & 1,6 & 3,0 \\
\hline Fitase $\left(\mathrm{FTU} \mathrm{kg}^{-1}\right)$ & 0,0 & 0,0 & 1.500 & 1.500 & 1.500 & 1.500 & 0,0 & 1.500 & 0,0 \\
\hline Lisina $\left(\mathrm{g} \mathrm{kg}^{-1}\right)$ & 13,1 & 11,7 & 11,7 & 11,7 & 11,7 & 11,7 & 10,8 & 10,8 & 10,1 \\
\hline Metionina + cistina $\left(\mathrm{g} \mathrm{kg}^{-1}\right)$ & 9,4 & 8,5 & 8,5 & 8,5 & 8,5 & 8,5 & 7,9 & 7,9 & 7,4 \\
\hline Treonina $\left(\mathrm{g} \mathrm{kg}^{-1}\right)$ & 8,5 & 7,6 & 7,6 & 7,6 & 7,6 & 7,6 & 7,0 & 7,0 & 6,6 \\
\hline Sódio $\left(\mathrm{g} \mathrm{kg}^{-1}\right)$ & 2,2 & 2,1 & 2,1 & 2,1 & 2,1 & 2,1 & 2,0 & 2,0 & 2,0 \\
\hline
\end{tabular}

(1)Dietas formuladas para atender as exigências nutricionais dos frangos de corte machos de desempenho médio, nas diferentes fases de criação, conforme Rostagno et al. (2011). ${ }^{(2)}$ Suplementado por kg de dieta: zinco, $55 \mathrm{mg}$; selênio, 0,18 mg; iodo, 0,70 mg; cobre, 10 mg; manganês, 78 mg; ferro, 48 mg. ${ }^{(3)}$ Suplementado por kg de dieta: ácido fólico, 0,64 mg; ácido pantotênico, 11,60 mg; biotina, 0,024 mg; butilhidroxitolueno (BHT), 2,0 mg; niacina, 14,8 mg; vitamina A, 8.000 UI; vitamina B1, 1,2 mg; vitamina E, 16,20 UI; vitamina B12, 10,8 mcg; vitamina B2, 4,8 mg; vitamina B6, 2,40 mg; vitamina D3, 2.000 UI; vitamina K3, 1,92 mg. ${ }^{(4)}$ Fitase microbiana de Citrobacter braakii. ${ }^{(5)}$ Para as formulações das dietas, utilizou-se a composição química dos ingredientes descrita por Rostagno et al. (2011), exceto para os seguintes ingredientes: fitase, em que se utilizou a atividade enzimática determinada de 9.615 FTU g-1 de enzima, segundo metodologia de Engelen et al. (1994); fosfato bicálcico, em que se utilizou os teores de fósforo disponível e cálcio determinados de 19,6 e 26,0 g $100 \mathrm{~g}^{-1}$, respectivamente, de acordo com as metodologias 965.17 e 935.13 de Horwitz (2005); e calcário calcítico, em que se utilizou o teor de cálcio determinado de 39,2 g $100 \mathrm{~g}^{1}$, conforme a metodologia 935.13 de Horwitz (2005). FTU, unidades de atividade da fitase; P-disp, fósforo disponível. 
$15 \mathrm{~kg}$ e respectiva precisão de 2, 2 ou $5 \mathrm{~g}$. Esses dados foram posteriormente utilizados para a realização dos cálculos de consumo de ração, ganho de peso e conversão alimentar das aves nos períodos de 8 a 35 e de 8 a 42 dias de idade.

Aos 35 e 42 dias de idade, três aves de cada unidade experimental foram selecionadas pelo peso individual próximo ao peso médio da parcela $( \pm 5 \%$ de variação) e abatidas para a retirada da tíbia esquerda. Para a determinação da percentagem das cinzas, método 942.05 (Horwitz, 2005), as tíbias foram identificadas, descarnadas, secas a $105^{\circ} \mathrm{C}$ em estufa ventilada, modelo MA035/1152 (Marconi, Piracicaba, SP), desengorduradas em éter etílico e incineradas a $600^{\circ} \mathrm{C}$ em forno mufla, modelo SP1200DM (SPLabor, São Paulo, SP).

A mortalidade das aves foi registrada diariamente na parte da manhã e da tarde, e foi considerada para a correção dos dados de desempenho. Todos os procedimentos experimentais adotados foram aprovados pela Comissão de Ética no Uso de Animais da Ufla (protocolo no 021/13).

Foram calculados o custo e o consumo para cada ração fornecida de 8 a 21, de 22 a 35 e de 36 a 42 dias de idade dentro de um mesmo PN.

Os dados de consumo de ração, ganho de peso e conversão alimentar nos períodos de 8 a 35 e de 8 a 42 dias de idade, assim como os resultados do teor de cinzas nas tíbias aos 35 e 42 dias de idade, foram submetidos à análise de variância com uso do programa Saeg (2007), e, quando esta foi significativa, os PN foram comparados pelo teste de agrupamento de médias de Scott \& Knott, a 5\% de probabilidade.

\section{Resultados e Discussão}

Houve efeito do PN sobre consumo de ração, ganho de peso e teor de cinzas na tíbia dos frangos de corte, no período de 8 a 35 dias de idade. De modo geral, ao se comparar os PN 1, 3, 5, 7 e 9 e os PN 2, 4, 6, 8 e 10, observou-se gradativa diminuição do teor de P-disp na ração fornecida de 8 a 21 dias de idade, concomitante com a redução no consumo de ração, o ganho de peso e a mineralização óssea dos frangos, independentemente da ração fornecida de 22 a 35 dias de idade (Tabela 2). A redução nesses parâmetros pode ser justificada pela importância do $\mathrm{P}$ para o desenvolvimento e o crescimento adequado dos animais (Bedford \& Partridge, 2010; Pereira et al., 2012).

No período de 8 a 35 dias de idade, ao se comparar o PN 1 e 3, verificou-se que a redução do teor de P-disp na dieta de 8 a 21 dias de idade de 3,9 para 2,5 $\mathrm{g} \mathrm{kg}^{-1}$, acompanhada da suplementação de $1.500 \mathrm{FTU} \mathrm{kg}^{-1}$, manteve desempenho e teor de cinzas ósseas semelhantes aos determinados para frangos alimentados com a dieta formulada com 3,9 $\mathrm{g} \mathrm{kg}^{-1}$ de P-disp de ração sem fitase (Tabela 2). Esse resultado corrobora o relatado por Shaw et al. (2011). A explicação para a manutenção desses parâmetros quando se reduz o nível de P-disp na ração é a suplementação da dieta com a fitase, pois essa enzima melhora o aproveitamento do P fítico pela ave (Fukayama et al., 2008; Donato et al., 2011; Shaw et al., 2011). A fitase catalisa a reação de desfosforilação do fitato em ésteres de fosfato de mioinositol menores e $\mathrm{P}$ inorgânico, de maneira que, após a ação catalítica da fitase sobre o fitato, o P fítico hidrolisado se torna disponível aos monogástricos e pode ser absorvido e aproveitado metabolicamente pela ave (Han et al., 2009).

No entanto, caso os valores de equivalência de $\mathrm{P}$ estabelecidos para a fitase, nos períodos isolados de 8 a 21 e de 22 a 35 dias (equivalência de 1,4 e 1,8 $\mathrm{g} \mathrm{kg}^{-1}$ de P-disp, respectivamente), sejam usados em um mesmo lote de frangos de corte, como no PN 4, não há redução do desempenho das aves, porém há menor mineralização óssea (Tabela 2). Isso significa que as dietas fornecidas de 8 a 35 dias de idade, dentro do PN 4 , não foram suficientes para atender à exigência de $\mathrm{P}$ das aves e assegurar a adequada mineralização óssea. Esse resultado está de acordo com pesquisas que têm mostrado que o valor de equivalência de $\mathrm{P}$ estabelecido para um determinado nível de suplementação de fitase é menor quando o parâmetro considerado é o teor de cinza óssea (Jendza et al., 2006; Han et al., 2009; Shaw et al., 2011).

Os resultados obtidos são indicativos de que a exigência de P-disp atualmente recomendada por Rostagno et al. (2011), de 3,9 $\mathrm{g} \mathrm{kg}^{-1}$ de $\mathrm{P}$ para o período de 8 a 21 dias de idade, está superestimada em $0,5 \mathrm{~g} \mathrm{~kg}^{-1} \mathrm{de}$ P. Isso confirma a hipótese de Slominski (2011), uma vez que o PN 5 resultou em desempenho e teor de cinzas na tíbia semelhantes aos determinados para frangos alimentados apenas com dietas controle (PN 1). Porém, ressalta-se que a redução do teor de P-disp para 2,0 $\mathrm{g} \mathrm{kg}^{-1}$ na fase de criação de 8 a 21 dias 
de idade só é recomendada quando a ração fornecida de 22 a 35 dias de idade é formulada para conter $3,4 \mathrm{~g} \mathrm{~kg}^{-1}$ de P-disp, sem fitase suplementar (Tabela 2).

Não houve efeito dos PN avaliados sobre a conversão alimentar nos períodos de 8 a 35 e de 8 a 42 dias de idade (Tabela 2). Isso ocorreu porque as aves que apresentaram maior consumo de ração tiveram maior ganho de peso, com conversão alimentar semelhante à daquelas que consumiram menos ração e ganharam menos peso. A média geral de conversão alimentar foi de 1,64, próxima ao valor de 1,70 relatado por Rostagno et al. (2011), para frangos de corte machos de desempenho superior, no período de 8 a 42 dias de idade.

Programas alimentares com restrição qualitativa incluem o fornecimento de uma ou mais dietas deficientes em um ou mais nutrientes, em uma ou mais fases de criação dos frangos (Butzen et al., 2013). Portanto, pode-se observar que, entre as dietas avaliadas no período de 8 a 35 dias de idade, aquelas que compõem os PN de 6 a 10 resultaram em menor ganho de peso das aves, o que indica provável restrição ou deficiência nutricional de P. Entretanto, conforme observado para os PN 6 e 8, embora as dietas fornecidas de 8 a 35 dias de idade tenham prejudicado o ganho de peso das aves nesse período, o fornecimento na fase seguinte da dieta, sem fitase suplementar, contendo 3,0 $\mathrm{g} \mathrm{kg}^{-1}$ de P-disp, foi suficiente para que os frangos recuperassem totalmente o ganho de peso até a idade de abate (Tabela 2). Isso indica que houve crescimento compensatório no período de 36 a 42 dias de idade. O crescimento compensatório tem sido definido como o crescimento rápido e atípico de um animal (comparado a outro de mesma idade, sexo e linhagem), depois de um retardo no crescimento inicial. Os mecanismos pelos quais isso ocorre ainda não estão completamente elucidados pela interação complexa entre fatores nutricionais, genéticos, fisiológicos, metabólicos, endócrinos e comportamentais (Butzen et al., 2013).

O crescimento compensatório mostrado pela recuperação total do ganho de peso das aves alimentadas com os PN 6 e 8 não significou obrigatoriamente que também houve deposição de minerais na tíbia de maneira compensatória. Chegou-se a essa conclusão porque, ao se considerar o teor de cinzas na tíbia aos 42 dias de idade, observou-se que, apenas com o PN 2, houve recuperação total da adequada deposição de minerais na tíbia, enquanto, para os PN 8 e 10, houve apenas melhora parcial desse parâmetro ósseo. Esses resultados são indicativos de que a deposição de minerais na tíbia de maneira compensatória no período de 36 a 42 dias de idade depende da intensidade da restrição de $\mathrm{P}$ da fase precedente (de 8 a 35 dias de idade). Já para os PN 1, 4, 5, 6, 7 e 9, houve manutenção da tendência dos resultados de cinzas ósseas, tanto aos 35 quanto aos 42 dias de idade das aves. O único comportamento adverso foi observado para o PN 3, no qual houve redução na taxa de mineralização óssea durante o período de 36 a 42 dias de idade.

Tabela 2. Consumo de ração, ganho de peso, conversão alimentar e teor de cinzas na tíbia de frangos de corte machos da linhagem Cobb-500 alimentados com diferentes planos nutricionais $(\mathrm{PN})^{(1)}$.

\begin{tabular}{|c|c|c|c|c|c|c|c|c|c|c|c|}
\hline \multirow[t]{2}{*}{$\mathrm{PN}$} & \multicolumn{3}{|c|}{$\begin{array}{c}\text { Rações conforme o período de criação } \\
\text { Pdisp }\left(\mathrm{g} \mathrm{kg}^{-1}\right) / \text { adição (+) ou não (-) de fitase }{ }^{(2)}\end{array}$} & \multicolumn{2}{|c|}{$\begin{array}{l}\text { Consumo de ração } \\
\text { (kg por ave) }\end{array}$} & \multicolumn{2}{|c|}{$\begin{array}{c}\text { Ganho de peso } \\
\text { (kg por ave) }\end{array}$} & \multicolumn{2}{|c|}{$\begin{array}{l}\text { Conversão alimentar } \\
\left(\mathrm{kg} \mathrm{kg}^{-1}\right) \\
\end{array}$} & \multicolumn{2}{|c|}{$\begin{array}{c}\text { Cinzas ósseas } \\
\left(\mathrm{g} 100 \mathrm{~g}^{-1} \text { de } \mathrm{MSD}^{(3)}\right)\end{array}$} \\
\hline & 8 a 21 dias & 22 a 35 dias & 36 a 42 dias & 8 a 35 dias & 8 a 42 dias & 8 a 35 dias & 8 a 42 dias & 8 a 35 dias & 8 a 42 dias & No $35^{\circ}$ dia & No $42^{\circ}$ dia \\
\hline PN 1 & $3,9 /-$ & $3,4 /-$ & $3,0 /-$ & $3,678 \mathrm{~A}$ & $5,142 \mathrm{~A}$ & $2,256 \mathrm{~A}$ & $2,941 \mathrm{~A}$ & $1,63 \mathrm{~A}$ & $1,74 \mathrm{~A}$ & $49,52 \mathrm{~A}$ & $50,97 \mathrm{~A}$ \\
\hline PN 2 & $3,9 /-$ & $1,6 /+$ & $3,0 /-$ & $3,658 \mathrm{~A}$ & $5,153 \mathrm{~A}$ & $2,256 \mathrm{~A}$ & $2,929 \mathrm{~A}$ & $1,62 \mathrm{~A}$ & $1,75 \mathrm{~A}$ & $48,28 \mathrm{~B}$ & $50,01 \mathrm{~A}$ \\
\hline PN 3 & $2,5 /+$ & $3,4 /-$ & $3,0 /-$ & $3,698 \mathrm{~A}$ & $5,191 \mathrm{~A}$ & $2,287 \mathrm{~A}$ & $2,971 \mathrm{~A}$ & $1,61 \mathrm{~A}$ & $1,74 \mathrm{~A}$ & $48,75 \mathrm{~A}$ & $49,27 \mathrm{~B}$ \\
\hline PN 4 & $2,5 /+$ & $1,6 /+$ & $3,0 /-$ & $3,624 \mathrm{~A}$ & $5,076 \mathrm{~A}$ & $2,213 \mathrm{~A}$ & $2,994 \mathrm{~A}$ & $1,63 \mathrm{~A}$ & $1,69 \mathrm{~A}$ & $47,67 \mathrm{~B}$ & $48,53 \mathrm{~B}$ \\
\hline PN 5 & $2,0 /+$ & $3,4 /-$ & $3,0 /-$ & $3,615 \mathrm{~A}$ & $5,079 \mathrm{~A}$ & $2,241 \mathrm{~A}$ & $2,913 \mathrm{~A}$ & $1,61 \mathrm{~A}$ & $1,74 \mathrm{~A}$ & $49,10 \mathrm{~A}$ & $50,03 \mathrm{~A}$ \\
\hline PN 6 & $2,0 /+$ & $1,6 /+$ & $3,0 /-$ & $3,524 \mathrm{~B}$ & $4,922 \mathrm{~B}$ & $2,143 B$ & $2,891 \mathrm{~A}$ & $1,64 \mathrm{~A}$ & $1,70 \mathrm{~A}$ & $47,20 \mathrm{~B}$ & $48,82 \mathrm{~B}$ \\
\hline PN 7 & $1,5 /+$ & $3,4 /-$ & $3,0 /-$ & $3,508 \mathrm{~B}$ & $4,863 \mathrm{~B}$ & $2,114 \mathrm{~B}$ & $2,811 \mathrm{~B}$ & $1,65 \mathrm{~A}$ & $1,72 \mathrm{~A}$ & $47,82 \mathrm{~B}$ & $49,40 \mathrm{~B}$ \\
\hline PN 8 & $1,5 /+$ & $1,6 /+$ & $3,0 /-$ & $3,365 \mathrm{C}$ & $4,774 \mathrm{~B}$ & $2,059 \mathrm{~B}$ & $2,883 \mathrm{~A}$ & $1,63 \mathrm{~A}$ & $1,65 \mathrm{~A}$ & $44,55 \mathrm{C}$ & $48,17 \mathrm{~B}$ \\
\hline PN 9 & $1,1 /+$ & $3,4 /-$ & $3,0 /-$ & $3,414 \mathrm{C}$ & $4,788 \mathrm{~B}$ & $2,115 \mathrm{~B}$ & $2,824 \mathrm{~B}$ & $1,61 \mathrm{~A}$ & $1,69 \mathrm{~A}$ & $47,99 \mathrm{~B}$ & $48,96 \mathrm{~B}$ \\
\hline PN 10 & $1,1 /+$ & $1,6 /+$ & $3,0 /-$ & $3,281 \mathrm{C}$ & $4,702 \mathrm{~B}$ & $2,035 \mathrm{~B}$ & $2,787 \mathrm{~B}$ & $1,61 \mathrm{~A}$ & $1,68 \mathrm{~A}$ & $44,91 \mathrm{C}$ & $48,30 \mathrm{~B}$ \\
\hline \multicolumn{4}{|c|}{ Efeito do plano nutricional (p-valor da Anova) } & $<0,01$ & $<0,01$ & $<0,01$ & $<0,05$ & $>0,05$ & $>0,05$ & $<0,01$ & $<0,01$ \\
\hline \multicolumn{4}{|c|}{ Coeficiente de variação (\%) } & 3,23 & 3,57 & 3,61 & 3,64 & 3,05 & 4,01 & 2,71 & 2,36 \\
\hline
\end{tabular}

${ }^{(1)}$ Médias seguidas de letras iguais, nas colunas, não diferem pelo teste de Scott \& Knott, a $5 \%$ de probabilidade. ${ }^{(2)} \mathrm{O}$ sinal (+) indica que a ração foi suplementada com 1.500 unidades de atividade da fitase (FTU) por kg, enquanto o sinal (-) indica que a ração não foi suplementada com fitase. ${ }^{(3)}$ MSD, matéria seca desengordurada. P-disp, fósforo disponível. 
Apesar de alguns trabalhos com frangos de corte já terem estudado a fitase, a maioria considera apenas o efeito da enzima sobre períodos de criação específicos e isolados como, por exemplo, de 1 a 21 dias de idade (Shaw et al., 2011; Rutherfurd et al., 2012; Olukosi et al., 2013). Além disso, até o presente momento, não há conhecimento de trabalho publicado que monitorasse os efeitos da inclusão da fitase durante as fases de criação de frangos de corte após o fornecimento da enzima na ração. Isso sinaliza a necessidade de mais pesquisas nessa área.

$\mathrm{O}$ nível de $\mathrm{P}$ da dieta deve atender não só as exigências das aves para a manutenção do desempenho, mas também deve fornecer quantidade de P suficiente para contribuir para a adequada mineralização óssea (Santos et al., 2008; Assuena et al., 2009; Barbosa et al., 2012). Os PN que resultaram no maior consumo de ração e ganho de peso dos frangos, no período de 8 a 42 dias, e no maior teor de cinzas nas tíbias, aos 42 dias de idade, foram os PN 1, 2 e 5. Assim, durante a produção comercial de um mesmo lote de aves, o uso da fitase em ração deficiente em $\mathrm{P}$ deve acontecer em apenas um único período de criação - de 8 a 21 ou de 22 a 35 dias de idade -, conforme observado, respectivamente, para os PN 5 e 2 (Tabela 2).

Ao se considerar que três PN proporcionaram resultados semelhantes de desempenho e teor de cinzas na tíbia dos frangos de corte, um bom critério para a recomendação de um único PN é o custo com a alimentação das aves no período de 8 a 42 dias de idade. Os custos com a alimentação para os PN 1, 2 e 5 foram estimados em, respectivamente, $\mathrm{R} \$ 4,17$, $\mathrm{R} \$ 4,15$ e $\mathrm{R} \$ 4,11$ por ave. Essas estimativas mostram que o PN 5 foi o mais indicado entre os três PN por possibilitar um menor custo com a alimentação, da ordem de $\mathrm{R} \$ 0,06$ para cada ave criada.

\section{Conclusões}

1. As reduções de fósforo em dietas de acordo com valores de equivalência de $\mathrm{P}$ estabelecidos para a fitase, em fases específicas de criação, não são adequadas quando se considera o período total de criação dos frangos de corte.

2. Com base na manutenção do desempenho e na adequada mineralização óssea de frangos de corte, o melhor plano nutricional é aquele no qual a redução de $\mathrm{P}$ pela equivalência estabelecida para a fitase é utilizada apenas no período de criação de 8 a 21 dias de idade das aves.

\section{Agradecimentos}

Ao Conselho Nacional de Desenvolvimento Científico e Tecnológico (CNPq), à Fundação de Amparo à Pesquisa de Minas Gerais (Fapemig) e ao Instituto Nacional de Ciência e Tecnologia de Ciência Animal (INCTCA), pelo apoio financeiro; e à DSM do Brasil Ltda., pelo fornecimento da enzima fitase.

\section{Referências}

ASSUENA, V.; JUNQUEIRA, O.M.; DUARTE, K.F.; LAURENTIZ, A.C.; FILARDI, R.S.; SGAVIOLI, S. Effect of dietary phytase supplementation on the performance, bone densitometry, and phosphorus and nitrogen excretion of broilers. Revista Brasileira de Ciência Avícola, v.11, p.25-30, 2009. DOI: 10.1590/S1516-635X2009000100005.

BARBOSA, N.A.A.; SAKOMURA, N.K.; BONATO, M.A.; HAUSCHILD, L.; OVIEDORONDON, E. Enzimas exógenas em dietas de frangos de corte: desempenho. Ciência Rural, v.42, p.1497-1502, 2012. DOI: 10.1590/S0103-84782012000800027.

BEDFORD, M.R.; PARTRIDGE, G.G. Enzymes in farm animal nutrition. Oxfordshire: CABI Publishing, 2010. 319p. DOI: 10.1079/9781845936747.0000.

BUTZEN, F.M.; RIBEIRO, A.M.L.; VIEIRA, M.M.; KESSLER, A.M.; DADALT, J.C.; DELLA, M.P. Early feed restriction in broilers. I: Performance, body fraction weights, and meat quality. Journal of Applied Poultry Research, v.22, p.251-259, 2013. DOI: 10.3382/japr.2012-00639.

DONATO, D.C.Z.; ALBUQUERQUE, R. de; GARCIA, P.D.S.R.; BALIEIRO, J.C.C. Desempenho de frangos de corte alimentados com rações contendo diferentes níveis de cálcio suplementadas com fitase. Revista Brasileira de Zootecnia, v.40, p.2161-2166, 2011. DOI: 10.1590/S1516-35982011001000014.

ENGELEN, A.J.; VAN DER HEEFT, F.C.; RANDSDORP, P.H.G.; SMIT, E.L.C. Simple and rapid determination of phytase activity. Journal of AOAC International, v.77, p.760-764, 1994.

FUKAYAMA, E.H.; SAKOMURA, N.S.; DOURADO, L.R.B.; NEME, R.; FERNANDES, J.B.K.; MARCATO, S.M. Efeito da suplementação de fitase sobre o desempenho e a digestibilidade dos nutrientes em frangos de corte. Revista Brasileira de Zootecnia, v.37, p.629-635, 2008. DOI: 10.1590/S1516-35982008000400007.

HAN, J.C.; YANG, X.D.; QU, H.X.; XU, M.; ZHANG, T.; LI, W.L.; YAO, J.H.; LIU, Y.R.; SHI, B.J.; ZHOU, J.F.; FENG, X.Y. Evaluation of equivalency values of microbial phytase to inorganic phosphorus in 22 to 42 dayold broilers. Journal of Applied Poultry Research, v.18, p.707-715, 2009. DOI: 10.3382/japr.2009-00029.

HORWITZ, W. (Ed.). Official methods of analysis. $18^{\text {th }} \mathrm{ed}$. Maryland: AOAC International, 2005. 1094p. 
JENDZA, J.A.; DILGER, R.N.; SANDS, J.S.; ADEOLA, O. Efficacy and equivalency of an Escherichia coliderived phytase for replacing inorganic phosphorus in the diets of broiler chickens and young pigs. Journal of Animal Science, v.84, p.3364-3374, 2006. DOI: $10.2527 /$ jas.2006-212.

KARIMI, A.; BEDFORD, M.R.; SADEGHI, G.H.; GHOBADI, $Z$. Influence of dietary nonphytate phosphorous levels and phytase supplementation on the performance and bone characteristics of broilers. Revista Brasileira de Ciência Avícola, v.13, p.43-51, 2011. DOI: 10.1590/S1516-635X2011000100007.

LICHTENBERG, J.; PEDERSEN, P.B.; ELVIGJOERGENSEN, S.G.; SKOV, L.K.; OLSEN, C.L.; GLITSOE, L.V. Toxicological studies on a novel phytase expressed from synthetic genes in Aspergillus oryzae. Regulatory Toxicology and Pharmacology, v.60, p.401-410, 2011. DOI: 10.1016/j.yrtph.2011.05.010.

NAVES, L. de P. Metodologias para quantificar fitato e uso de fitases em rações para frangos de corte. 2012. 152p. Tese (Doutorado) - Universidade Federal de Lavras, Lavras.

OLUKOSI, O.A.; KONG, C.; FRUNJI, F.; AJUWON, K.M.; ADEOLA, O. Assessment of a bacterial 6phytase in the diets of broiler chickens. Poultry Science, v.92, p.2101-2108, 2013. DOI: 10.3382/ps.2012-03005.

PEREIRA, R.; MENTEN, J.F.M.; ROMANO, G.G.; SILVA, C.L.S.; ZAVARISE, K.C.; BARBOSA, N.A.A. Eficiência de uma fitase bacteriana na liberação de fósforo fítico em dietas de frangos de corte. Arquivo Brasileiro de Medicina Veterinária e Zootecnia, v.64, p.137-144, 2012. DOI: 10.1590/S0102-09352012000100020.
ROSTAGNO, H.S.; ALBINO, L.F.T.; DONZELE, J.L.; GOMES, P.C.; OLIVEIRA, R.F.; LOPES, D.C.; FERREIRA, A.S.; BARRETO, S.L.T.; EUCLIDES, R.F. Tabelas brasileiras para aves e suínos: composição de alimentos e exigências nutricionais. 3.ed. Viçosa: Ed. da UFV, Departamento de Zootecnia, 2011. $252 \mathrm{p}$.

RUTHERFURD, S.M.; CHUNG, T.K.; THOMAS, D.V.; ZOU, M.L.; MOUGHAN, P.J. Effect of a novel phytase on growth performance, apparent metabolizable energy, and the availability of minerals and amino acids in a lowphosphorus cornsoybean meal diet for broilers. Poultry Science, v.91, p.1118-1127, 2012. DOI: 10.3382/ps.2011-01702.

SAEG: sistema para análises estatísticas. Versão 9.1. Viçosa: Ed. da UFV, 2007.

SANTOS, F.R.; HRUBY, M.; PIERSON, E.E.M.; REMUS, J.C.; SAKOMURA, N.K. Effect of phytase supplementation in diets on nutrient digestibility and performance in broiler chicks. Journal of Applied Poultry Research, v.17, p.191-201, 2008. DOI: 10.3382/ japr.2007-00028.

SHAW, A.L.; HESS, J.B.; BLAKE, J.P.; WARD, N.E. Assessment of an experimental phytase enzyme product on live performance, bone mineralization, and phosphorus excretion in broiler chickens. Journal of Applied Poultry Research, v.20, p.561-566, 2011. DOI: 10.3382/japr.2011-00389.

SLOMINSKI, B.A. Recent advances in research on enzymes for poultry diets. Poultry Science, v.90, p.20132023, 2011. DOI: 10.3382/ps.2011-01372.

Recebido em 14 de outubro de 2013 e aprovado em 26 de dezembro de 2013 